\title{
MULTI-RESPONSE OPTIMIZATION FOR DETERMINING OPTIMAL CUTTING PARAMETERS IN THE HARD TURNING TUNGSTEN CARBIDE USING CBN INSERTS
}

\author{
QUOC TUAN NGUYEN ${ }^{1}$, MINH TUAN NGO ${ }^{2 *}$ \& VAN NGHI PHAN ${ }^{3}$ \\ ${ }^{1}$ Associate Professor and Head of Office for Undergraduate Training, Thai Nguyen University of Technology, 3/2 street, Tich \\ Luong Ward, Thai Nguyen City, Vietnam \\ ${ }^{2,3}$ Lecturer of Faculty of Mechanical Engineering, Thai Nguyen University of Technology, 3/2 street, Tich Luong ward, Thai
} Nguyen City, Vietnam

\begin{abstract}
In recent years, sintered tungsten carbide has been used to manufacture molds or steel rolling shafts. The Cubic Boron Nitride is a super hard material used to machine hard-to-cut substances as tungsten carbide. The aim of the research is to decide the optimal slitting conditions in the hard turning tungsten carbide with both the reactions (the quality surface and the flank wear). This study has designed an RSM model with trial points in the center of the face. Analysis of variance performed with the quality surface along with flank wear showed that the experimental data set was statistically significant. The composite desirability for the quality surface along with flank wear was determined. The outcomes of optimizing multi responses using the composite desirability showed that the composite desirability obtain the maximum value 0.9487 with depth of cut $0.1 \mathrm{~mm}$, cutting speed $36 \mathrm{~m} / \mathrm{min}$ and feed rate $0.11 \mathrm{~mm} / \mathrm{rev}$. Hence, the contour plot for the composite desirability with the feed rate $0.11 \mathrm{~mm} / \mathrm{rev}$ indicated that the composite desirability is greater than 0.9 with the cutting speed less $50 \mathrm{~m} / \mathrm{min}$ and the cutting depth less $0.2 \mathrm{~mm}$.
\end{abstract}

KEYWORDS: Hard Turning, Tungsten Carbide, Multi-Response, Optimization, Surface Roughness, Flank Wear

Received: May 21, 2020; Accepted: Jun 11, 2020; Published: Aug 04, 2020; Paper Id.: IJMPERDJUN2020611

\section{INTRODUCTION}

Cermeted tungsten carbide WC were growing more widely employed for dies as well as shapes because of their higher mechanical attributes like high strength, high hardness and high wear resisting features at high temperature etc. However, the forming of product from the blank by EDM, grinding or polishing is very difficult, has high cost and is quite time consuming. In recently years, with the development of material technology, many new cutting device substances may be utilized for the hard substance machining process. Several researchers analyzed methods to enhance the effectiveness of machining cermeted tungsten carbide process using the milling and turning method.

Some authors studied and analyzed the consequences of the cutting variables on the surface roughness in the hard machining tungsten carbide. Kim et al. (2012) experimented on the consequences of variables turning procedure with a chamfered diamond edge on the quality surface by using simulated and investigational method. The study determined that turning tungsten carbide procedure utilizing the chamfered device produced better surface roughness than using the conventional tool. Coppini et al. (2013)analyzed the effects of the cutting variables on the quality surface in the firm turning tungsten carbide WC utilizing the full factorial design. However, this study only investigates with the low cutting speed from $10 \mathrm{~m} / \mathrm{min}$ to $30 \mathrm{~m} / \mathrm{min}$ and uses with two levels. Coppini et 
al. (2018)contrast to the quality surface in the internal turning sintered tungsten carbide using PCD inserts with those in the grinding process. The results showed that the achieved surface roughness in the internal turning sintered tungsten carbide is identical to those normally acquired in milling functions, hence can substitute milling in commercial activities. Other research studies (Zębala et al., 2015; Zębala \& Kowalczyk, 2014; Zębala \& Kowalczyk, 2015) also analyzed the influence of cutting variables on quality surface in WC-Co turning process PCD inserts. However, most of these studies only used the lesser scope of cutting speed as well as used PCD inserts.

Other researchers investigated the tool wear in the tungsten carbide machining process. HEO et al. (2003) analyzed the influences of machining conditions on the tool wear as well as cutting force in the firm turning cemented tungsten carbide using PCD inserts. The results of this research showed that the tool wear rate increases with boosting of the cutting rate. Wu et al. (2018)examined the influences of the tool wear on the cutting pressure in the micro milling of tungsten carbide employing PCD tool. The study's results showed that the most wear is on the tip and the flank face. Liu et al. (2003)also noticed that the flank wear is the main type of wear in machining tungsten carbide with CBN inserts. Okada et al. (2016) analyzed the tool wear behaviour and cutting pressure in the cutting of tungsten carbides utilizing a diamond covered ball end mill.

In brief, there are many researchers who examined the consequences of the cutting variables on a single response (the quality surface or the tool wear) in the machining sintered tungsten carbide. This study aims at the maximization of various cutting variables for multi-response the quality surface and the flank wear by using the response with Face Central Composition design. We focused the turning sintered tungsten carbide $25 \mathrm{wt} \%$ Co having high hardness $82.5 \mathrm{HRA}$ with the CBN inserts.

\section{EXPERIMENT DETAIL}

In the current research, Ra and FW were observed in investigating the machining operation of the turning tungsten carbide process using CBN inserts. Ra and FW are analysis with the cutting parameters including the cutting speed, depth of cut as well as feed rate. The experiments are performed on the CNC turning center of Mazak Company, as figure 1. The cutting device used in the turning tungsten carbide process was the CBN inserts having code ISO CNGA120408-DNC250 and made by DINE tool manufacturer (Korea). This research used the tungsten carbide work pieces having high hardness (82.5 HRA) and having 25\%wt cobalt binder of Zhuzhou Better Company. The quality surface of the turning surface has estimated through Mitutoyo's SJ210 irregular gauge (Figure 1). The flank wear of CBN tool are measured with machining distance $100 \mathrm{~m}$ by the by digital microscope VHX-7000 by Keyence. The value levels of the cutting parameters in the turning process were selected based on the proposal of the cutting device manufacturer (DINE) and the outcomes of earlier studies and shown in table 1.

Response surface methodology with face central composite design (RSM-FCCD) model is used to design the experimental matrix included 18 trials with 6-face central trials, 8 corner trials and 4 center trials, shown in table 2 . All trials were performed with random experimental order (run Order) designed by Minitab 18 software. 
Table 1: The Value Levels of the Cutting Parameters

\begin{tabular}{|l|c|c|c|c|}
\hline \multirow{2}{*}{ Parameters } & \multirow{2}{*}{ Units } & \multicolumn{3}{|c|}{ Levels } \\
\cline { 3 - 5 } & & $\mathbf{- 1}$ & $\mathbf{0}$ & $\mathbf{1}$ \\
\hline Depth of cut $(d)$ & $\mathrm{mm}$ & 0.1 & 0.25 & 0.4 \\
\hline Cutting speed $(V)$ & $\mathrm{m} / \mathrm{min}$ & 30 & 50 & 70 \\
\hline Feed rate $(f)$ & $\mathrm{mm} / \mathrm{rev}$ & 0.1 & 0.15 & 0.2 \\
\hline
\end{tabular}

Table 2: The Experimental Matrix and Results

\begin{tabular}{|c|c|c|c|c|c|c|c|c|c|}
\hline Std. Order & Run Order & Pt Type & Blocks & $\mathbf{d}(\mathbf{m m})$ & $\mathbf{V}(\mathbf{m} / \mathbf{m i n})$ & $\mathbf{f}(\mathbf{m m} / \mathbf{r e v})$ & $\mathbf{F W}(\boldsymbol{\mu m})$ & $\mathbf{R a}(\boldsymbol{\mu m})$ & $\mathbf{d c}$ \\
\hline 12 & 1 & -1 & 1 & 0.25 & 70 & 0.15 & 326.7 & 0.633 & 0.3309 \\
\hline 10 & 2 & -1 & 1 & 0.4 & 50 & 0.15 & 219.4 & 0.727 & 0.6940 \\
\hline 14 & 3 & -1 & 1 & 0.25 & 50 & 0.2 & 282.2 & 1.239 & 0.4126 \\
\hline 1 & 4 & 1 & 1 & 0.1 & 30 & 0.1 & 147.8 & 0.312 & 0.9692 \\
\hline 19 & 5 & 0 & 1 & 0.25 & 50 & 0.15 & 237.7 & 0.566 & 0.6798 \\
\hline 7 & 6 & 1 & 1 & 0.1 & 70 & 0.2 & 285.8 & 1.577 & 0.3248 \\
\hline 3 & 7 & 1 & 1 & 0.1 & 70 & 0.1 & 307 & 0.224 & 0.4807 \\
\hline 5 & 8 & 1 & 1 & 0.1 & 30 & 0.2 & 163.4 & 1.361 & 0.6235 \\
\hline 13 & 9 & -1 & 1 & 0.25 & 50 & 0.1 & 214 & 0.190 & 0.8258 \\
\hline 20 & 10 & 0 & 1 & 0.25 & 50 & 0.15 & 230.1 & 0.567 & 0.7012 \\
\hline 4 & 11 & 1 & 1 & 0.4 & 70 & 0.1 & 350.5 & 0.424 & 0.1515 \\
\hline 8 & 12 & 1 & 1 & 0.4 & 70 & 0.2 & 355.9 & 2.210 & 0.0000 \\
\hline 15 & 13 & 0 & 1 & 0.25 & 50 & 0.15 & 235 & 0.551 & 0.6908 \\
\hline 17 & 14 & 0 & 1 & 0.25 & 50 & 0.15 & 233.4 & 0.540 & 0.6976 \\
\hline 11 & 15 & -1 & 1 & 0.25 & 30 & 0.15 & 189.2 & 0.727 & 0.7670 \\
\hline 9 & 16 & -1 & 1 & 0.1 & 50 & 0.15 & 186 & 0.533 & 0.8234 \\
\hline 18 & 17 & 0 & 1 & 0.25 & 50 & 0.15 & 237.2 & 0.557 & 0.6832 \\
\hline 16 & 18 & 0 & 1 & 0.25 & 50 & 0.15 & 234 & 0.571 & 0.6894 \\
\hline 6 & 19 & 1 & 1 & 0.4 & 30 & 0.2 & 170.5 & 1.443 & 0.5815 \\
\hline 2 & 20 & 1 & 1 & 0.4 & 30 & 0.1 & 181.9 & 0.363 & 0.8745 \\
\hline
\end{tabular}

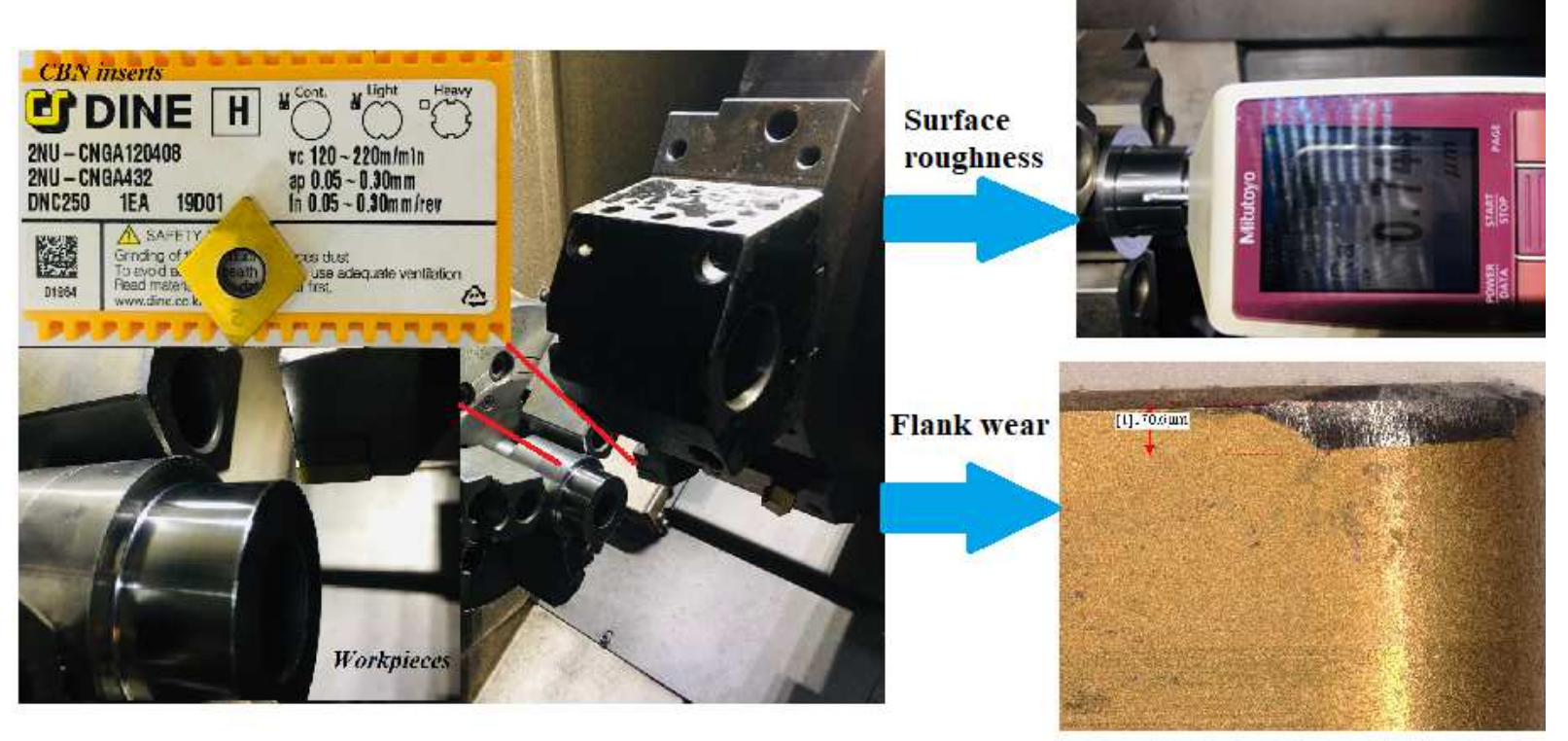

Figure 1: Experimental Set Up. 


\section{RESULTS AND DISCUSSIONS}

\section{Effect of Cutting Parameters on Surface Roughness}

ANOVA analysis for the quality surface in the firm turning tungsten carbide was performed with a significance level of 0.05. The results of ANOVA analysis using RSM-FCCD model are presented in Table 3. The P value of the design was lower than 0.0001 (statistically significant). The influences of investigated elements, as well as their interactions on quality surface, were presented in the pareto diagram (figure 2). The feed rate (FR) has the strongest consequence on the quality surface in the hard turning tungsten carbide. And other factors included depth of cut (DOC), cutting speed (CTS) along with interactions (CTS*FR, CTS*CTS, DOC*CTS and FR*FR) significantly affect on the quality surface. Additionally, DOC*DOC and DOC * FR interactions have a weak influence on quality surface.

\section{Pareto Chart of the Standardized Effects (response is $\mathrm{Ra}, \alpha=0.05$ )}

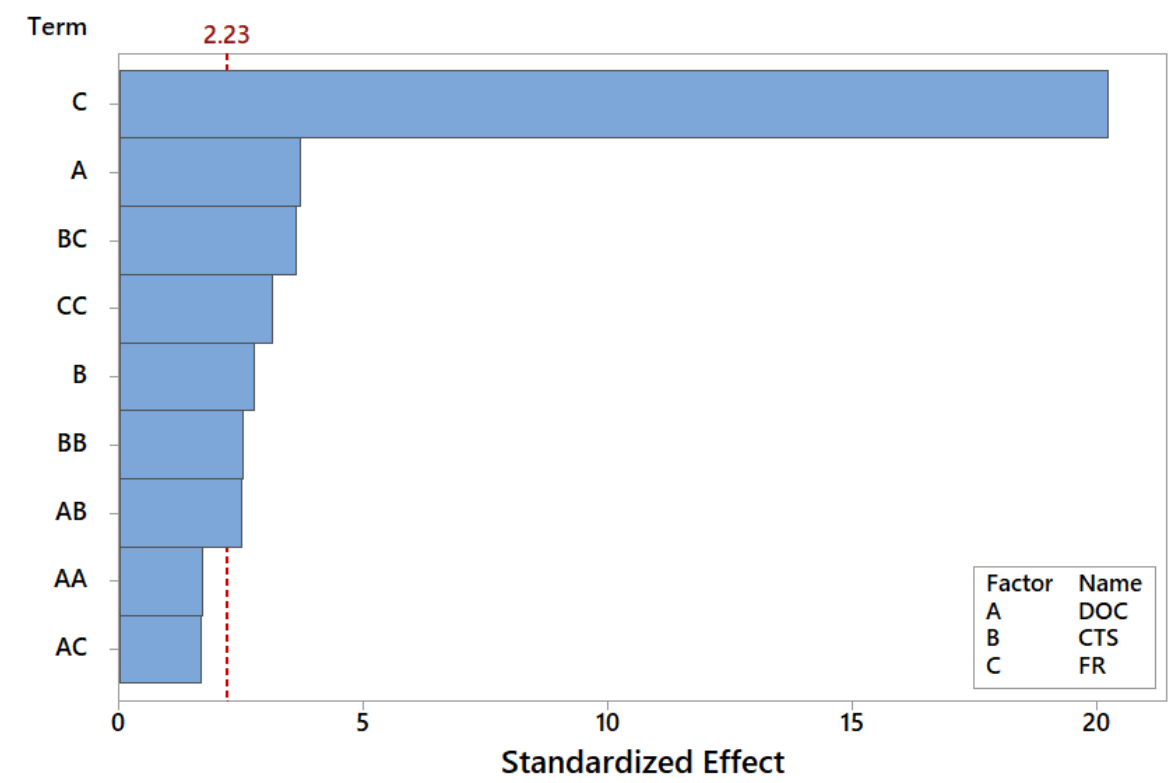

Figure 2. Pareto Chart for Surface Roughness.

Table 3: The Result of Analysis ANOVA for the Surface Roughness

\begin{tabular}{|c|c|c|c|c|c|}
\hline Source & DF & Adj SS & Adj MS & F-Value & P-Value \\
\hline Model & 9 & 5.12717 & 0.56969 & 58.37 & 0.000 \\
\hline Linear & 3 & 4.20040 & 1.40013 & 143.46 & 0.000 \\
\hline DOC & 1 & 0.13433 & 0.13433 & 13.76 & 0.004 \\
\hline CTS & 1 & 0.07436 & 0.07436 & 7.62 & 0.020 \\
\hline FR & 1 & 3.99171 & 3.99171 & 409.00 & 0.000 \\
\hline Square & 3 & 0.71095 & 0.23698 & 24.28 & 0.000 \\
\hline DOC*DOC & 1 & 0.02804 & 0.02804 & 2.87 & 0.121 \\
\hline CTS*CTS & 1 & 0.06295 & 0.06295 & 6.45 & 0.029 \\
\hline FR*FR & 1 & 0.09494 & 0.09494 & 9.73 & 0.011 \\
\hline 2-Way Interaction & 3 & 0.21582 & 0.07194 & 7.37 & 0.007 \\
\hline DOC*CTS & 1 & 0.06119 & 0.06119 & 6.27 & 0.031 \\
\hline DOC*FR & 1 & 0.02703 & 0.02703 & 2.77 & 0.127 \\
\hline CTS*FR & 1 & 0.12760 & 0.12760 & 13.07 & 0.005 \\
\hline Error & 10 & 0.09760 & 0.00976 & & \\
\hline
\end{tabular}




\begin{tabular}{|l|c|c|c|c|c|}
\hline Lack-of-Fit & 5 & 0.09691 & 0.09691 & 2.01 & 0.112 \\
\hline Pure Error & 5 & 0.00069 & 0.00014 & & \\
\hline Total & 19 & 5.22477 & & & \\
\hline
\end{tabular}

The consequence of cutting rate, depth of cut along with feed rate on the main of the quality surface is described in figure 3. The plot show that Ra changes slightly when changing the cutting speed and depth of cut, but increases rapidly while boosting the feed rate from $0.1 \mathrm{~mm} / \mathrm{rev}$ to $0.2 \mathrm{~mm} / \mathrm{rev}$. The optimal cutting parameters for the surface roughness also are determined by using response optimizer function in Minitab, as figure 4. The results investigated that the quality surface obtain the least value with the depth of cut $0.1 \mathrm{~mm}$, cutting rate $30 \mathrm{~m} / \mathrm{min}$ and feed rate $0.1 \mathrm{~mm} / \mathrm{rev}$.

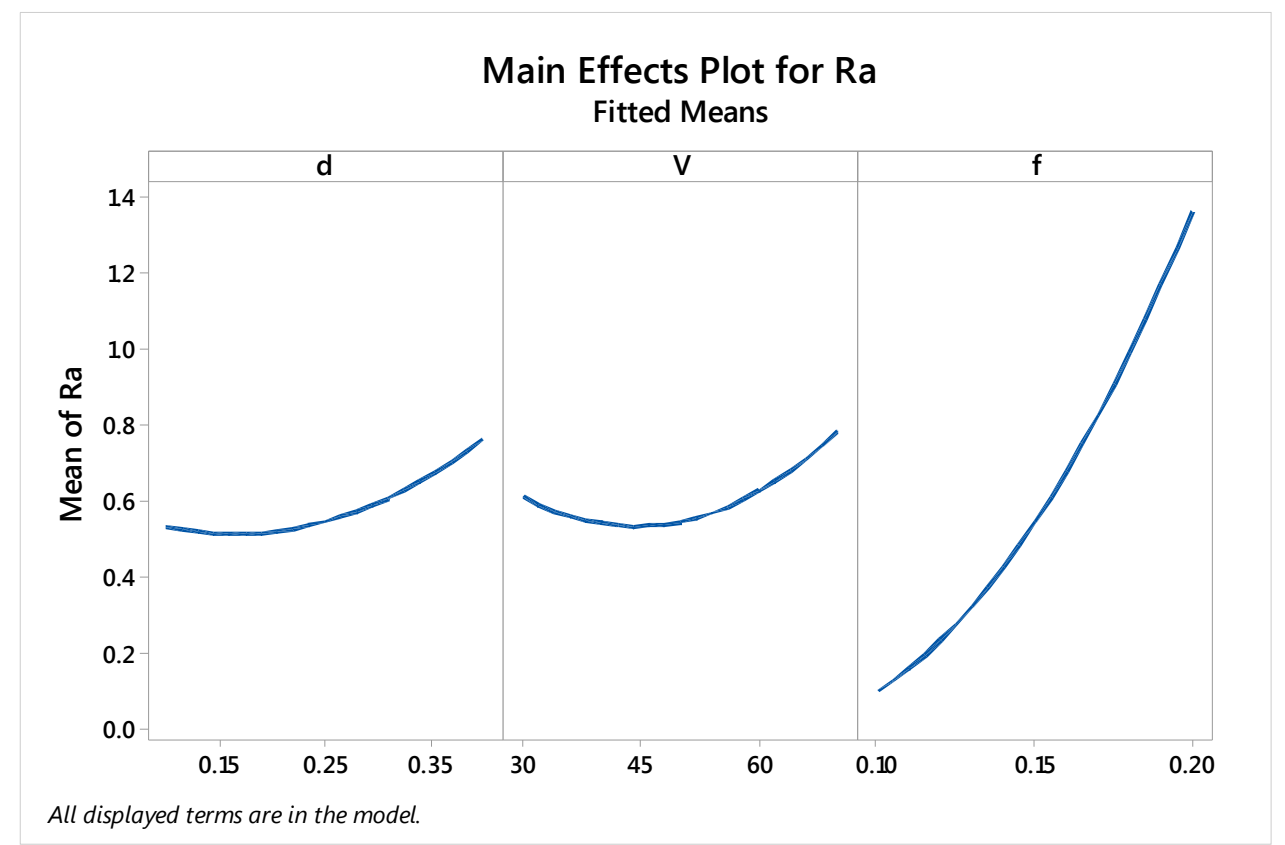

Figure 3: The Main Effects Plot for the Surface Roughness.

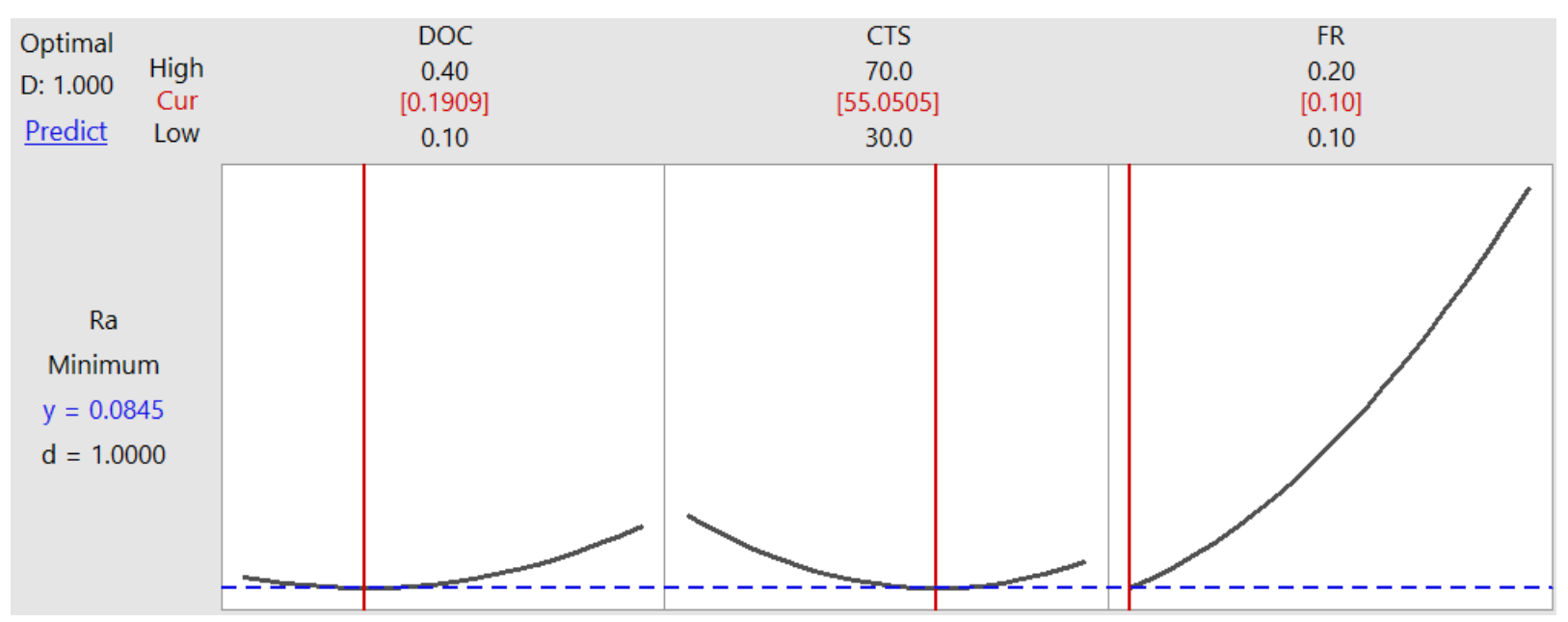

Figure 4: The Optimal Cutting Parameters for the Surface Roughness.

\section{Effect of Cutting Parameters on Flank Wear}

The outcomes of ANOVA test show that most of the investigated factors have a strong effect on the flank wear excluding interactions DOC*FR and DOC*DOC because of most factors having a low $\mathrm{P}$ value. The outcomes have been shown in 
the pare to chart for the flank wear (Figure 5). The Pareto chart shows that the feed rate is the greatest effect element on the flank wear succeeded through DOC, CTS*FR, FR*FR, CTS, CTS*CTS and DOC*CTS.

Table 4: The Result of Analysis ANOVA for the quality Surface

\begin{tabular}{|c|c|c|c|c|c|}
\hline Source & DF & Adj SS & Adj MS & F-Value & P-Value \\
\hline Model & 9 & 68278.3 & 7586.5 & 28.86 & 0.000 \\
\hline Linear & 3 & 63630.6 & 21210.2 & 80.69 & 0.000 \\
\hline DOC & 1 & 3541.9 & 3541.9 & 13.47 & 0.004 \\
\hline CTS & 1 & 59768.4 & 59768.4 & 227.38 & 0.000 \\
\hline FR & 1 & 320.4 & 320.4 & 1.22 & 0.295 \\
\hline Square & 3 & 3942.4 & 1314.1 & 5.00 & 0.023 \\
\hline DOC*DOC & 1 & 2439.1 & 2439.1 & 9.28 & 0.012 \\
\hline CTS*CTS & 1 & 1783.7 & 1783.7 & 6.79 & 0.026 \\
\hline FR*FR & 1 & 670.8 & 670.8 & 2.55 & 0.141 \\
\hline 2-Way Interaction & 3 & 705.2 & 235.1 & 0.89 & 0.477 \\
\hline DOC*CTS & 1 & 655.2 & 655.2 & 2.49 & 0.145 \\
\hline DOC*FR & 1 & 0.0 & 0.0 & 0.00 & 0.993 \\
\hline CTS*FR & 1 & 50.0 & 50.0 & 0.19 & 0.672 \\
\hline Error & 10 & 2628.5 & 262.9 & & \\
\hline Lack-of-Fit & 5 & 2590.0 & 2590.0 & 1.99 & 0.137 \\
\hline Pure Error & 5 & 38.6 & 7.7 & & \\
\hline Total & 19 & 70906.8 & & & \\
\hline
\end{tabular}

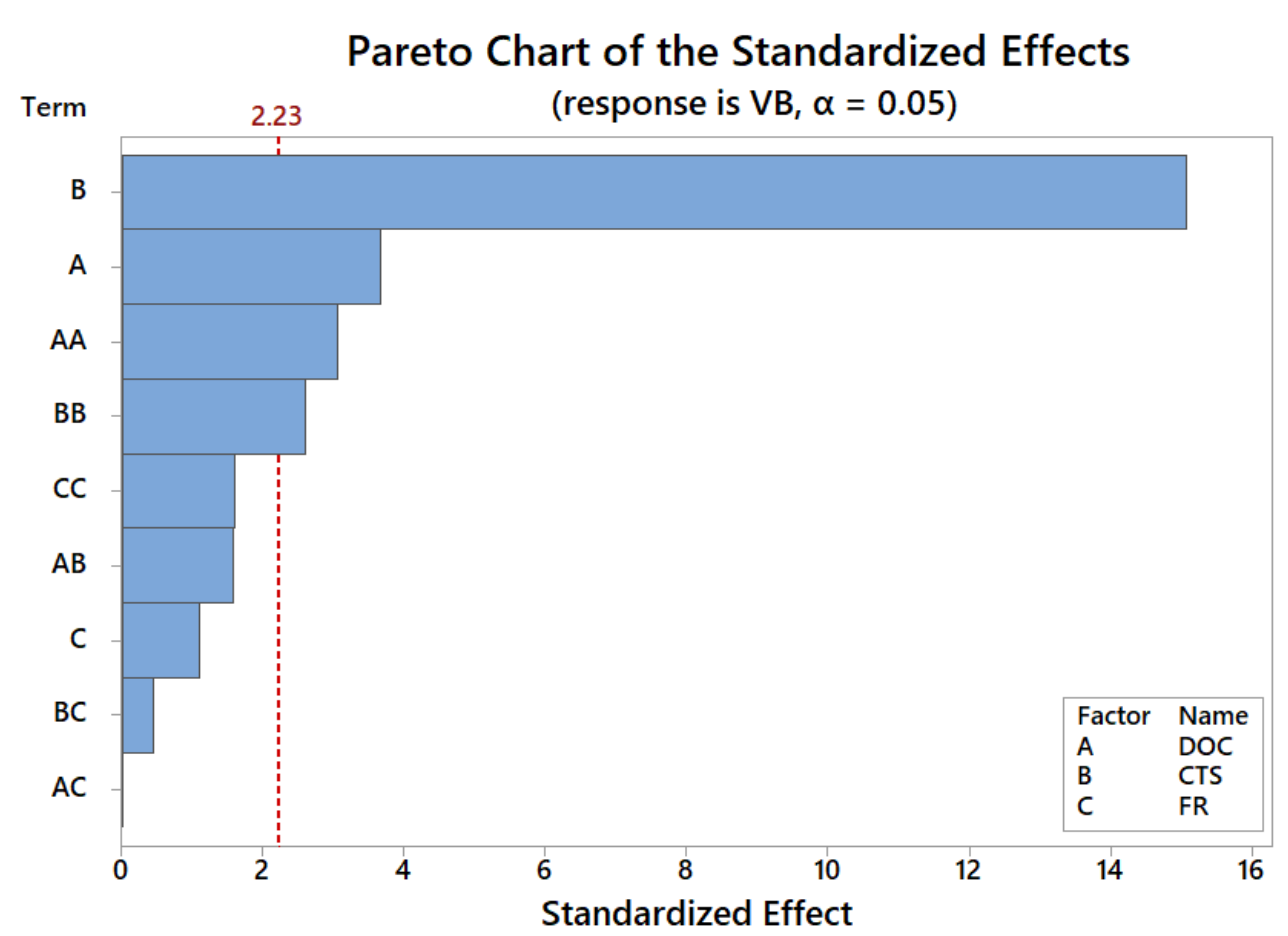

Figure 5: Pareto Chart for the Flank Wear.

Figure 6 describes the effect of the cutting parameter in hard turning tungsten carbide on the flank wear of CBN insert. The result arrived was that the tool wear increases rapidly with tool wear from $30 \mathrm{~m} / \mathrm{min}$ to $70 \mathrm{~m} / \mathrm{min}$. Besides, the amount of back wear increases with increasing the depth of cut from $0.1 \mathrm{~mm}$ to $0.3 \mathrm{~mm}$. However, the flanks wear decreases if the cutting depth continues to increase to $0.4 \mathrm{~mm}$. The results of optimizing the cutting states for the flank 
wear show that the flank wear reaches to the minimum value with the depth of cut $0.1 \mathrm{~mm}$, cutting rate $30 \mathrm{~m} / \mathrm{min}$ and feed rate $0.1364 \mathrm{~mm} / \mathrm{rev}$.

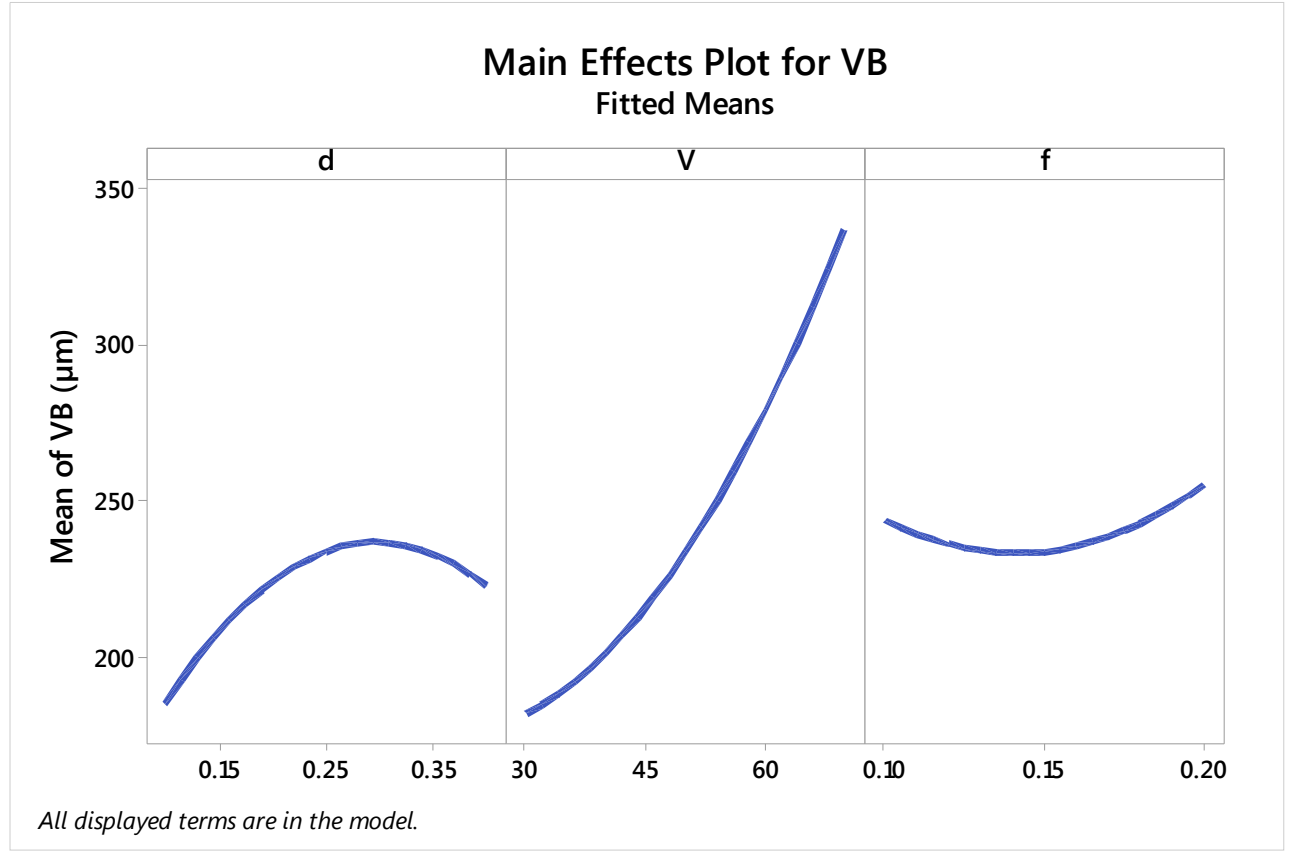

Figure 6: Main Effects Plot for the Flank Wear.

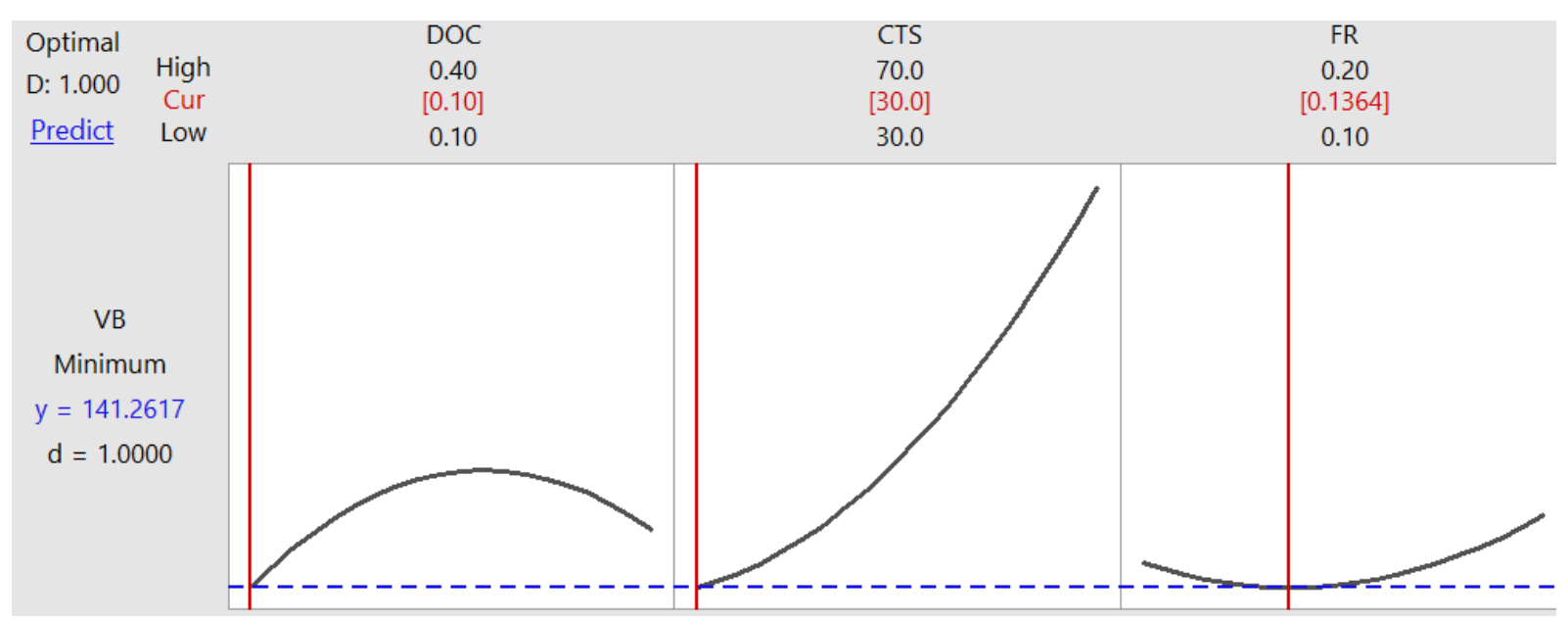

Figure 7: The Optimal Cutting Parameters for the Flank Wear.

\section{MULTI-RESPONSE OPTIMIZATION}

Response optimization is useful to assess the impact of cutting variables on the quality surface or the flank wear. However, the quality surfaces, as well as the flank wear, reach to the minimum value with different cutting parameters. Whereas, the best combined cutting parameters should produce the minimum quality surface as well as flank wear. The optimized cutting parameters were determined by using the multi - response optimization method. This technique was initiated by Derringer and Suich (1980) for optimizing quality characteristic problems in the industry. This method used the composite desirability (D) determined following the equation (1).

$$
D=\sqrt[r_{1}+r_{2}+\cdots+r_{n}]{d_{1}^{r_{1}}, d_{2}^{r_{2}}, d_{n}^{r_{3}} \ldots d_{n}^{r_{n}}}
$$


In where: $d_{i}$ is the desirability for each response

$m_{1}$ is the importance of the each response

$\mathrm{n}$ is the number of responses in the research

If the importances of the responses are the same, the composite desirability function can be modified as equation (2).

$$
D=\sqrt[n]{d_{1}, d_{2}, \ldots d_{n}}
$$

The input factors using maximal composite profitability were observed to be the most favourable variable states. The desirability functions for each response are determined by transforming the estimated responses into the scale-free values ranged from 0 to 1 .

If it is desirable to least a response, the individual profitability was computed as:

$$
a_{i}=\left\{\begin{array}{lc}
1 & \text { if } y \leq L_{i} \\
\left(\frac{v_{i}-y_{i}}{v_{i}-L_{i}}\right)^{W_{i}} & \text { if } L_{i}<y_{i}<U_{i} \\
0 & \text { ify } \geq U_{i}
\end{array}\right.
$$

If it is desirable to maximize a response, the individual profitability was computed as:

$$
d_{i}=\left\{\begin{array}{lr}
0 & \text { if } y_{\mathrm{i}} \leq L_{i} \\
\left(\frac{y_{i}-L_{i}}{V_{i}-z_{i}}\right)^{W_{i}} & \text { if } L_{i}<y_{i}<U_{i} \\
1 & \text { if } y_{\mathrm{i}} \geq U_{i}
\end{array}\right.
$$

If it is desirable to aim a response, the individual profitability was computed as:

$$
d_{i}=\left\{\begin{array}{lr}
0 & \text { if } y_{i} \leq L_{i} \\
\left(\frac{y_{i}-L_{i}}{T_{i}-L_{i}}\right)^{w_{i}} & \text { if } L_{\mathrm{i}}<y_{\mathrm{i}}<T_{\mathrm{i}} \\
1 & \text { if } y_{\mathrm{i}}=T_{\mathrm{i}} \\
\left(\frac{u_{i}-y_{i}}{v_{i}-T_{i}}\right)^{w_{i}} & \text { if } T_{i}<y_{i}<U_{i} \\
0 & \text { if } y_{\mathrm{i}} \geq U_{i}
\end{array}\right.
$$

In where: $d_{i}$ is the desirability

$w_{i}$ is the weight of the each response

$y_{i}$ is the measured value of response

$L_{i}$ lowest value of response

$U_{i}$ highest value of response

$T_{i}$ target value of response

In the research, The desirability's for the quality surface as well as flank wear were calculated by equation (3) because they are desirable to maintain the minimum value. Their weight and important values are kept constant and equal to 1 . So the composite desirability is calculated by equation (2) and the results are indicated in table 1. 

Tungsten Carbide using CBN Inserts

Figure 8 depicts the effective plot of the both reactions (the surface roughness and the flank wear) as well as the maximization outcomes. The perpendicular lines within the cells depict present best parametric positions; also the parallel dotted lines depict the present reaction values. The value of mixture profitability (D) has noted as 0.9487 . The current optimal cutting parameter settings are depth of cut $0.1 \mathrm{~mm}$, cutting speed $36 \mathrm{~m} / \mathrm{min}$ and feed rate $0.11 \mathrm{~mm} / \mathrm{rev}$. To indicate the responsiveness of the outcomes, contour plots for composite profitability with holding feed rate $0.11 \mathrm{~mm} / \mathrm{rev}$ have been plotted as represented in Figure 9. The near-optimal region was located close to the left hand corner region of the plot with a higher mixture profitability value and it gradually reduces as moving right as well as upwards. Based on the contour plot, a suitable cutting condition with the feed rate $0.11 \mathrm{~mm} / \mathrm{rev}$, the cutting rate was less than $50 \mathrm{~m} / \mathrm{min}$ and the cutting depth is lower than $0.2 \mathrm{~mm}$ can be selected so that the composite desirability is greater than 0.9 .

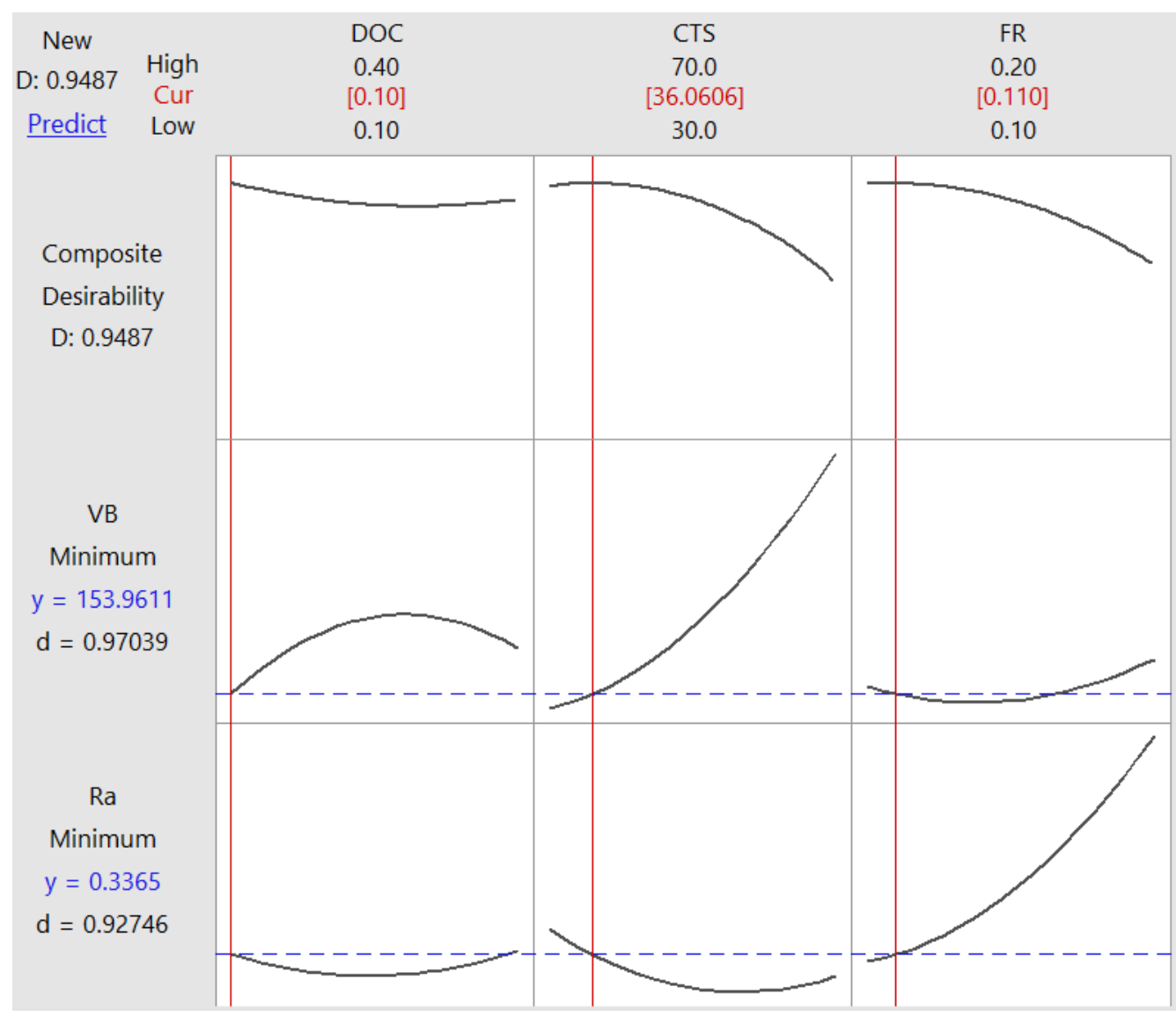

Figure 8: The Optimal Cutting Parameters for the Multi-Response Optimization. 


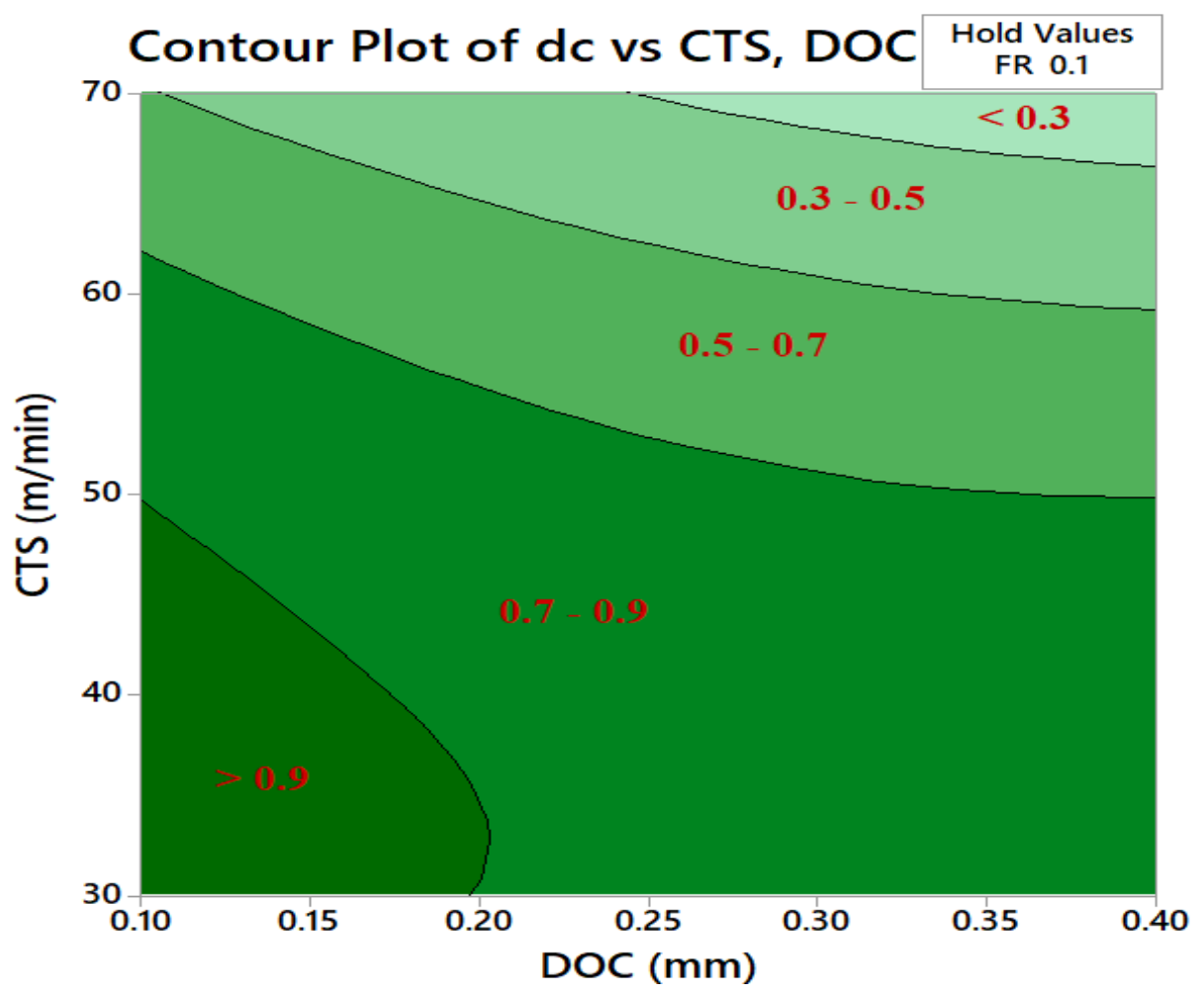

Figure 9: The Contour Plot for the Composite Desirability with Holding Feed Rate 0.11 mm/rev.

\section{CONCLUSIONS}

In this study, the effects of cutting variables on the quality surface as well as the flank wear in the hard turning tungsten carbide using the CBN inserts are investigated and studied by using the RSM model. Outlining the primary characteristics, the succeeding determinations can be presented:

- Examination of differences performed with the quality surface and flank wear showed that the experimental data set was statistically significant. The cutting speed, cutting depth and their square have a strong effect on the flank wear, and the feed rate (FR) has the strongest effect on the quality surface in the hard turning tungsten carbide using CBN tool.

- The composite desirability for the quality surface as well as flank wear was determined. The composite desirability obtained the maximum value 0.9487 with depth of cut $0.1 \mathrm{~mm}$, cutting speed $36 \mathrm{~m} / \mathrm{min}$ and feed rate $0.11 \mathrm{~mm} / \mathrm{rev}$.

- The contour plot for the composite desirability with the feed rate $0.11 \mathrm{~mm} / \mathrm{rev}$ indicated that the composite desirability is greater than 0.9 with the cutting speed less $50 \mathrm{~m} / \mathrm{min}$ and the cutting depth less $0.2 \mathrm{~mm}$.

\section{FUNDING}

The study was supported by Vietnam Ministry of Education and Training with the project number of B2019-TNA-01.

\section{ACKNOWLEDGEMENTS}

This research got the assistance of Vietnam Ministry of Education and Training and Thai Nguyen University of Technology, Thai Nguyen University with the project number of B2019-TNA-01. 


\section{REFERENCES}

1. Coppini, N. L., Diniz, A. E., Bonandi, M., De Souza, E. M., \& Baptista, E. A. (2013). Hard turning of sintered cemented carbide parts: A shop floor experience. Procedia CIRP, 8, 368-373. https://doi.org/10.1016/j.procir.2013.06.118

2. Coppini, Nivaldo Lemos, Diniz, A. E., Lacerda, F. S., Bonandi, M., \& Baptista, E. A. (2018). Internal turning of sintered carbide parts: tool wear and surface roughness evaluation. Journal of the Brazilian Society of Mechanical Sciences and Engineering, 40(4). https://doi.org/10.1007/s40430-018-1139-z

3. Darshan, Chetan, et al. "Comparative Evaluation of Untextured and Textured WC Inserts Under Dry and Near Dry Machining of C45 Steel."International Journal of General Engineering and Technology (IJGET) 6. 5, Aug - Sep 2017; 1-16

4. Derringer, G., \& Suich, R. (1980). Simultaneous Optimization of Several Response Variables. Journal of Quality Technology, 12(4), 214-219. https://doi.org/10.1080/00224065.1980.11980968

5. HEO, S. J., Miyamoto, T., $\quad$ Hanasaki, $\quad$ S., $\quad \& \quad$ Fujiwara, $\quad J . \quad$ (2003). 超硬合金の切削に関する研究一旋削におけるpcd工具の摩耗機構と切削抵抗一. 精密工学会誌, 69(12), 1724-1728.

6. Kim, M. J., Lee, J. K., Hwang, Y., Cha, D. H., Kim, H. J., \& Kim, J. H. (2012). Experimental study of the diamond turning characteristics of tungsten carbide (Co 0.5\%) when using a chamfered diamond bite. Journal of the Korean Physical Society, 61(9), 1390-1394. https://doi.org/10.3938/jkps.61.1390

7. Liu, K., Li, X. P., Rahman, M., \& Liu, X. D. (2003). CBN tool wear in ductile cutting of tungsten carbide. Wear, 255(7-12), 1344-1351. https://doi.org/10.1016/S0043-1648(03)00061-9

8. Malagi, Ravindra R., Sanjeevkumar R. Chougula, and Ravira J. Shetty. "Prediction of cutting force in turning of ti-6al-4v under minimum quantitylubrication (Mql) usingresponse surface model and fuzzylogic model." International Journal of Mechanical and Production Engineering Research and Development 8.6 (2018): 263-274.

9. Okada, M., Yoshida, A., Furumoto, T., Watanabe, H., Asakawa, N., \& Otsu, M. (2016). Mechanisms and characteristics of direct cutting of tungsten carbide using a diamond-coated carbide end mill. International Journal of Advanced Manufacturing Technology, 86(5-8), 1827-1839. https://doi.org/10.1007/s00170-015-8324-3

10. Sivaraman, Viswanathan, and Subramanian Prakash. "Optimization of Cutting Parameters in Hard Turning of AISI O1 Steel Using Pvd TiAlN Coated Carbide Insert."International Journal of Mechanical and Production Engineering Research and Development (IJMPERD) 10. 1, Feb 2020, 459-468

11. Shihan, Muhammed, et al. "Experimental Investigation and Design Optimization of Face MillingParameters on Monel K-500 by Doe Concept." International Journal of Mechanical and Production Engineering Research and Development (IJMPERD) 7.4 (2017): 403-410.

12. Wu, X., Li, L., He, N., Zhao, G., Jiang, F., \& Shen, J. (2018). Study on the tool wear and its effect of PCD tool in micro milling of tungsten carbide. International Journal of Refractory Metals and Hard Materials, 77, 61-67. https://doi.org/10.1016/j.ijrmhm.2018.07.010

13. Zębala, W., \& Kowalczyk, R. (2014). Cutting data influence on cutting forces and surface finish during sintered carbide turning. Key Engineering Materials, 581, 148-153. https://doi.org/10.4028/www.scientific.net/KEM.581.148

14. Zębala, W., \& Kowalczyk, R. (2015). Estimating the effect of cutting data on surface roughness and cutting force during WCCo turning with PCD tool using Taguchi design and ANOVA analysis. International Journal of Advanced Manufacturing Technology, 77(9-12), 2241-2256. https://doi.org/10.1007/s00170-014-6382-6 
15. Zębala, W., Kowalczyk, R., \& Matras, A. (2015). Analysis and optimization of sintered carbides turning with PCD tools. Procedia Engineering, 100(January), 283-290. https://doi.org/10.1016/j.proeng.2015.01.369

\section{AUTHOR'S PROFILE}

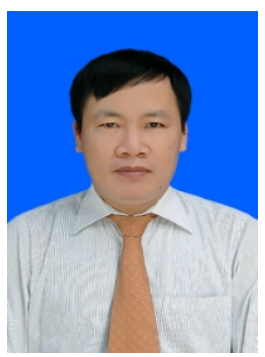

Quoc Tuan Nguyen was born in 1969, in Viet Nam. He received his Ph.D. from Ha Noi University of Science and Technology in 2003. He is the head of training office and works as a lecturer, researcher and Associate professor of Faculty of Mechanical Engineering in Thai Nguyen University of Technology, Vietnam. His main research is in are Cutting tool design, Hard machining process,Cutting process optimization, nontraditional machining process and CAD/CAM-CAE. He is a Reviewer for Vietnam Journal of Science and Technology (VJST), TNU Journal of Science and Technology and Vietnam Mechanics Association \& national journals and international journal of science. He has authored/co-authored nearly 21 National journal, International Journal papers and International Conference papers.

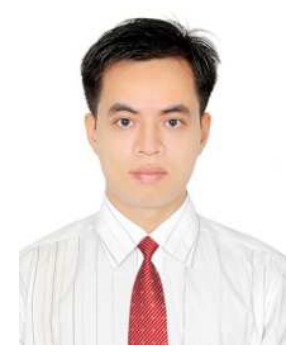

Minh Tuan Ngo was born in 1985, in Thai Nguyen city, Viet Nam. He completed B.Sc., M.Sc. and Ph.D. degrees from Ha Noi Science and Technology University in 2007, 2011 and 2018 respectively. He has worked as Design Engineer in Kosaka Seiki Company, Aichi province, Japan from the years of 2007 to 2009. And now, he works as a lecturer and researcher of Faculty of Mechanical Engineering in Thai Nguyen University of Technology, Vietnam. His main work is in gear hobbing process, Machining process optimization, Mechanical engineering, Hard machining process, CAD/CAMCAE and Software in Mechanical engineering \& Design of Experiments (DOE). He is a Reviewer for Vietnam Journal of Science and Technology (VJST), TNU Journal of Science and Technology. He authored/co-authored nearly 17 International Journal papers and International Conference papers.

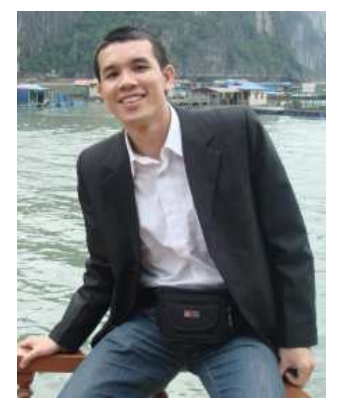


Van Nghi Phan was born in 1984, in Nghe An Province, Viet Nam. He completed the B.Sc. and M.Sc. degrees from Thai Nguyen University of Technology. He works as a lecturer and researcher of Faculty of Mechanical Engineering in Thai Nguyen University of technology, Vietnam. He has taught the cutting tool and CAD/CAM-CNC course. His main works are Cutting tool design, Machine design, Machining process optimization, Mechanical engineering and Hard machining process. He is a Reviewer for TNU Journal of Science and Technology. He has authored/co-authored nearly 10National journal, International Journal papers and International Conference papers. 

